\title{
O CUIDADO DE SI E A EXPERIÊNCIA: [RE]EXISTÊNCIAS NA EDUCAÇÃO
}

\author{
Anísia Gonçalves Dias Neta
}

\section{RESUMO}

A associação entre Benjamin e Foucault que esse trabalho pretende, traz à tona o cuidado de si presente nas aulas de "Hermenêutica do Sujeito" e nos textos de "Dits et Écrits" em Michel Foucault, e a experiência encontrada nos ensaios "Experiência e Pobreza" e "O Narrador" em Walter Benjamin.

Palavras-chave: Cuidado de Si; Experiência; Educação; Ética.

\section{THE CARE OF THE SELF AND THE EXPERIENCE: [RE] EXISTENCES IN EDUCATION}

\begin{abstract}
The association between Benjamin and Foucault that this work intends to bring to light is the care of the self present in the classes of "Hermeneutics of the Subject" and in the texts of "Dits et Écrits" in Michel Foucault, and the experience found in the essays "Experience and Poverty" and "The Storyteller" in Walter Benjamin.
\end{abstract}

Key words: Care of the self; Experience; Education; Ethic.

\section{Introdução}

O cuidado de si nos interpela sobre quem é o "eu" de que se deve cuidar e que tipo de cuidado é esse que se deve ter. A experiência nos leva para um lugar do saber, da compreensão, da sabedoria. Quando propomos um cuidado de si na educação, a partir de Foucault, estamos nos referindo ao eu dos agentes educacionais, professor e estudantes que se relacionam no processo ensinoaprendizagem; o que não significa um eu cognoscente, antes, sujeitos de ações. Ações essas que cuidam de realizar um retorno sobre si mesmo, a partir de experiências e exercícios, com fins de transformação. No entanto, encontramos 
com frequência, muitas forças sociais e políticas que se apresentam como nós, como pontos de intersecção na trama das relações e que engendram estratégias e práticas de sujeição aos sujeitos da educação de modo que nos encontramos frágeis e minúsculos. Quando propomos a ideia de experiência na educação, a partir de Benjamin, o fazemos a partir do entendimento do quanto a agilidade das informações estão distantes da ideia de saber, de apreender um saber, de compreender algo. E que esse aprendizado, essa compreensão de um saber se dá num sentido amplo, abrangendo o cognitivo e o emocional. Assim, apresentamos nesse texto, alguns desses processos biopolíticos presentes na área da educação contemporânea, bem como propomos, a partir do cuidado de si foucaultiano e da ideia de experiência em Benjamin, uma melhor compreensão da educação na contemporaneidade e apontamentos de possibilidades e caminhos viáveis para uma vida não fascista, que conhece muito bem a distância entre o ensino, muitas vezes de natureza dogmática, e a educação, cuja matéria prima é a sabedoria para a existência plena, motivo de felicidade, cuja possibilidade, só existe, para Benjamin, em uma "história aberta".

Ao pensar sobre cuidado de si na educação, não podemos nos furtar de voltar ao conceito de vida plena dos gregos para começar a nossa reflexão. Não que essa visita signifique uma valorização tal e qual os gregos tinham sobre a ideia de cuidado de si, ou ainda, sobre sua pedagogia. No entanto, a tomemos aqui como um ponto de partida para pensarmos o cuidado de si no cenário educacional.

\begin{abstract}
O Alcibíades, de Platão, pode ser considerado como ponto de partida: a questão do "cuidado de si mesmo" - epimeleia heautou - aparece nesse texto como o quadro geral no interior do qual o imperativo do conhecimento de si toma sua significação. A série de estudos que é possível encarar a partir daí poderia formar, assim, uma história do "cuidado de si mesmo", entendido como experiência, e assim também como técnica que elabora e transforma essa experiência (FOUCAULT, 2014, 350).
\end{abstract}

A relação de discipulado entre Alcibíades e Sócrates é o fundamento da primeira e segunda aula do dia 06 de janeiro de 1982 de Foucault no Curso $A$ Hermenêutica do Sujeito (2010), e será também a que permeará toda a obra, aparecendo aqui e ali, em momentos decisivos. Três são os diálogos em que 
Platão apresenta Alcibíades: Protágoras, Banquete e Alcibíades. No diálogo que leva o nome dele, Alcibíades é jovem, no limiar da vida adulta, e demonstra pretensões políticas. Tem, portanto, que demonstrar suas competências para bem governar os outros. Mas Sócrates, ao interpelá-lo, percebe o quanto seus inimigos estão bem mais preparados que ele e o quanto o conselho délfico, conhece-te a ti mesmo, na visão do conhecimento de si como conhecimento do divino que leva à sabedoria se faz necessário nesse momento. Sócrates, nesse diálogo, após a promessa de Alcibíades que começaria a cuidar de si e da justiça, exclama o que poderia ser chamado posteriormente de mau presságio, visto a derrocada do governo de Alcibíades, confundindo-se com a própria derrocada de Atenas. Acresce-se a esse fato a condenação à morte de Sócrates. ${ }^{1}$

De acordo com a versão desse texto em inglês ${ }^{2}$, Sócrates temia que diante da promessa do Alcibíades em cuidar de si e da justiça -, o Estado, sua moralidade, as condutas, os costumes de um povo, um modo de ser determinado por forças políticas e sociais seriam então uma ameaça muito forte para que Alcibíades cumprisse seu intento. Nesse texto podemos inferir que essa potência da cidade, ou dos costumes dos cidadãos, ou ainda, a potência de Atenas reverberada no exercício da política é forte o suficiente para influenciar o cuidado que devemos ter sobre nós mesmos e sobre o processo de cuidado com os outros para que se alcance a justiça.

Aqui conseguimos identificar o problema com o qual Alcibíades irá se deparar em sua vida adulta, que será verbalizado para Sócrates, anos mais tarde, em seu apogeu como político, no diálogo do Banquete, quando Alcibíades, embriagado, brada que descuidou de si, para cuidar de Atenas.

\footnotetext{
${ }^{1}$ Destaco aqui o receio de Sócrates quanto à intenção de Alcibíades em cuidar de si e da justiça (versão em português). "Faço votos para que perseveres nesse intento; contudo, tenho meus receios, não por descrer de tua natureza; é que, considerando a força de nosso povo, temo que eu e tu venhamos a ser dominados por ela" (PLATÃO, Diálogos: Fedro - Cartas - Primeiro Alcibíades. Trad. direta do grego: Carlos Alberto Nunes. $2^{\mathrm{a}}$ edição revisada. Belém: EDUFPA, 2007, 288).

${ }^{2}$ Destaco aqui o receio de Sócrates quanto à intenção de Alcibíades em cuidar de si e da justiça (versão em inglês) "And I hope that you will persist; although have fears, not because I doubt you; but I see the power of the state, which maybe too much for both of us" (PLATO. Alcibiades I. Translated by Benjamin /Jowett. Project Gutemberg Etext \#1676: Champaing: Carnegie-Mellon University. 1999, 56).
}

Professora de Filosofia do Instituto Federal de Educação, Ciência e Tecnologia Baiano - IFBaiano, campus Senhor do Bonfim. Mestranda em Filosofia pela UECE. Brasileira, residente em Feira de Santana - BA. Email: anisia neta@hotmail.com 
Com o exemplo do Alcibíades, sobre o qual Foucault se debruçou para entender sobre o cuidado de si, podemos então inferir quais problemas teríamos hoje, ao enveredarmos pelos caminhos do cuidado de si na educação, nos questionando quais seriam as forças, ou o que seria essa potência engendrada na educação da contemporaneidade.

E aqui, Walter Benjamin nos traz uma grande contribuição acerca do quanto o homem moderno se distanciou de seu autoentendimento como ser integral: racional e biológico, ou seja, de sua unidade mente e corpo. Um cartesianismo extremado nos levou a cristalizar uma imagem de ser humano bem como uma formatação educacional que impede a liberdade de criatividade, imaginação, e da presença do inconsciente e das percepções das sensações como fundamentais para o aprendizado. Encontramos em Benjamin um conceito que concerne a essa tonalidade cara à educação: o conceito de experiência, onde educar e ensinar se distanciam. O contexto de uma confusão a esse respeito se apresenta como uma grande força biopolítica que impede os agentes educacionais a desempenharem bem seus papéis no processo educacional de ensino-aprendizagem. Em alemão ensinar (lehren) tem a mesma raiz da palavra doutrina (lehre) o que significa que esse conceito não está isento de um dogmatismo e por que não dizer, com sérios riscos de uma prática ideológica. Benjamin acerta essa diferença a partir de uma crítica epistemológica em "Questões introdutórias de crítica do conhecimento" em que ele comenta sobre a diferença entre o aspecto doutrinário do ensino e o contexto dirigido à educação da citação autorizada, no tratado medieval (BENJAMIN, 1984, 50).

A prática que predomina na formação pedagógica vem acompanhada de outros pensamentos e comportamentos insensíveis à educação, que exibem uma potência de inserção e influência nas práticas de ensino como um todo, como fascismos, dogmatismos e práticas de controle, sujeição, domínio, docilização, uma porta aberta para o assalto aos subjetivismos.

Paralelo a isso, a educação atrelada à lógica utilitária e econômica (a partir de regulações sobre as políticas governamentais e sobre seus objetivos), e justamente, com o advento da tecnociência, onde não só a contemporaneidade, mas o ensino tem experimentado a aceleração como um modus vivendi do qual 
nosso tempo presente não escapa, compõem um grande cenário do que seria obstáculo para um cuidado de si e uma experiência educacional que reflitam no processo pedagógico e na educação como um todo.

\section{Educação e Problematizações}

O campo da educação é, sobretudo, por excelência, o campo da interiorização da sociedade, da sua cultura e também da reinvenção da humanidade. É através dela que sedimentamos os costumes - sugeridos, especialmente em Benjamin, a partir de Hábitos e atenção (BENJAMIN, 1987, 247) -, construímos uma sociedade e suscitamos suas mudanças.

A potência política e social exercida sobre os sujeitos de uma sociedade, tem o campo da educação como lugar privilegiado para fazer valer sua ação de influência. Assim, o processo de formação pedagógica se torna uma importante estratégia de ação, visto que a relação professor-estudante é a via onde os processos de sedimentação e interiorização da cultura melhor se dará.

Como já é sabido, temos atualmente, no cenário educacional, várias falas em prol de uma crítica dos fundamentos da educação, no entanto, a prática formativa muitas vezes não acompanha esse percurso teórico, assim como a teoria tem de correr para dar conta das mudanças, nos processos educacionais da contemporaneidade, que mesmo sem uma teoria, já se vê na prática. Vejamos algumas contextualizações.

O processo ensino-aprendizagem é uma via de mão dupla, onde o professor não apenas ensina, como aprende quando ensina, e o estudante não apenas aprende, mas também pode participar do processo ensinando. No entanto, não é fácil identificarmos na prática pedagógica onde isso seja levado a cabo constantemente. Percebemos uma educação ainda que se pretende formadora de conceitos e de subjetividades, partindo de princípios sobre 0 homem e a sociedade, fazendo muitas vezes, multiplicar os fascismos e os 
dogmatismos, bem como práticas de sujeição. Ou seja, exercendo a potência política e social sobre os sujeitos.

Para Walter Benjamin, o sujeito deve ser desnudado de todos os conceitos filosóficos que foram sendo agregados à ideia de homem ao longo do tempo, para que assim, ele se faça como criatura que participa da construção de si mesmo ao passo que se constitui no mundo.

Outro momento em que podemos identificar a força aniquiladora de subjetividades singulares é uma educação voltada única e exclusivamente para a transmissão de conhecimentos. O momento cartesiano trouxe várias mudanças para a modernidade, especialmente a lente com a qual se olha o mundo. Essa lente epistemológica tem estado presente na educação, a despeito de tantas críticas aos seus fundamentos.

O processo ensino-aprendizagem visto meramente como transmissão de conteúdos racionais e objetivos não é apenas uma visão reduzida do processo do conhecimento, bem como é uma degenerescência do conceito de educação, que cai na armadilha da razão e consequentemente, do utilitarismo.

A redução do processo do conhecimento se dá porque não se aprende ou se ensina apenas através de conceitos. Não somos apenas razão e não aprendemos somente através dos processos racionais. Aprendemos também a partir da experiência, do tempo de maturação destas, com os afetos, entre outros. Inclusive aprendemos coisas das quais não sabemos conceituar.

Aqui, mais uma vez podemos recorrer a Benjamin para entender que 0 projeto de racionalidade humanista para educação, do período lluminista, é visto por ele como fracassado. Especialmente depois da Primeira Guerra Mundial, Benjamin percebeu que essa racionalidade não deu conta, que o humanismo não passou de uma falácia. No entanto, é importante destacar, que, a despeito da falência do projeto humanista, Benjamin depositava esperança na racionalidade humana para uma educação emancipatória e rica em saberes, que promova abundância do ser.

O conceito de experiência deste autor, em Experiência e Pobreza, bem como em $O$ narrador, ajuda-nos a perceber o quanto o tempo, a maturação e a sedimentação são necessárias para construir a sabedoria. Mais que isso, a 
experiência é formada e se faz formativa a partir de elementos que não são apenas conscientes, mas inconscientes. É na distração da consciência que a experiência é mais do que aprendida, é internalizada, fazendo parte da vida do sujeito.

Quando a experiência se faz dessa maneira, então é capaz de ser transmitida, não sem misturar e assimilar elementos do corpo que a digeriu. Para apreender uma experiência, ou uma narrativa, é necessário um ruminar. Benjamin utiliza exatamente essa palavra $\left(g r u ̈ b e l n^{3}\right)$ dando a entender o quanto o processo de experiência é vagaroso, processual, digestório; requer elementos que não são necessariamente conscientes para se somar aos conscientes; e o quanto ele é bem maior do que o aprendizado racional, se fazendo não apenas com a mente, com a consciência, mas com o corpo, com a matéria, com os sentidos. Corpo e alma não se separam. Pensamos e aprendemos com tudo que somos. Nessa esteira, podemos pensar numa educação que conta também com o aprendizado do corpo. O ruminar não simboliza apenas a reflexão como labor do pensamento, da razão, mas que a maturação da vivência e da experiência são importantes para o aprendizado e para a vida.

O processo educacional se dá de maneira inteira e íntegra - o narrador é o justo (BENJAMIN, 1994, 221) -, pois educação não se faz como administração e burocratização do saber, senão como compromisso profissional que é engajamento e extensão da própria vida - $A$ vida dos estudantes (BENJAMIN, 1986, 155). Educação, para Benjamin, é um processo contínuo, sempre nãoacabado, visto que o homem é esse ser em processo, que nunca será conhecido inteira e definitivamente.

A degenerescência da educação também se dá pelo seu viés ético, pois ao invés do objetivo último ser uma educação para a vida e cidadania, a educação tem se prestado a objetivos concretos, de ordem utilitária e econômica. Há na

\footnotetext{
${ }^{3}$ A palavra grübler significa o homem ocupado a grübeln, verbo que pode ser traduzido por sonhar, meditar, maturar, ruminar e cuja etimologia reenvia a graben, cavar, e a Grab, túmulo; trata-se, portanto, de um maturar ou de um meditar ligado ao sem-fundo e à morte: no contexto de A Origem do Drama Barroco Alemão, à meditação infinita e melancólica do alegorista. Sérgio Paulo Rouanet traduz Grübler por "o meditativo". (BENJAMIN, W. A Origem do Drama Barroco Alemão, São Paulo, Brasiliense, 1984, p. 198).
}

Professora de Filosofia do Instituto Federal de Educação, Ciência e Tecnologia Baiano - IFBaiano, campus Senhor do Bonfim. Mestranda em Filosofia pela UECE. Brasileira, residente em Feira de Santana - BA. Email: anisia neta@hotmail.com 
sociedade contemporânea uma corrida contra o tempo que impregna também o processo educativo, que se traduz em uma corrida por produtividade.

Precisamos nos mostrar produtivos em resultados de provas (provas semestrais, simulados, ENEM, vestibulares, seleções, concursos), depois precisamos mostrar produtividade em publicações, em conhecimento. Importa menos a prática do conhecimento adquirido ou produzido e mais a produção do conhecimento. Nesse quesito temos contra nós não o tempo, mas o modo de encará-lo; toda uma condução de condutas que exigem prazos e formatos. Benjamin em $A$ Vida dos Estudantes, nos lembra que:

A deformação do espírito criador em espírito profissional, que vemos atuando por toda parte, apossou-se por inteiro da universidade, isolandoa da vida intelectual criativa e não enquadrada na administração pública. (BENJAMIN, 1986, 155)

O espírito profissional, ao qual Benjamin se refere, pode ser entendido aqui como uma educação que se pretende para fins específicos e utilitários e até mesmo econômicos, e ainda como uma administração do ser professor que se ocupa muito mais em administrar seu tempo entre aulas e produção, bem como com os processos burocráticos do ensino, em detrimento de uma educação para a vida, criativa e livre.

A tecnociência ou, para se usar os termos apropriados para educação, as tecnologias de informação, engendradas no ambiente educacional, trazem muitos benefícios que podem ser vistos de várias formas: educação a distância, aprendizado em rede, participação e troca de vivências e aprendizado com várias localidades - o que amplia a visão e o contexto a ser abordado -, rapidez e facilidade ao acesso às informações necessárias para o aprendizado, grande quantidade de arquivos que podem ser armazenados em pequeno espaço e com fácil mobilidade, programas que nos auxiliam no aprendizado, etc.

No entanto, um nítido comportamento tem acontecido com a educação em meio a essas mudanças presentes em nossa sociedade tecnológica: queremos que o processo ensino-aprendizagem seja também rápido, instantâneo como o download de um arquivo. As tecnologias são ótimas ferramentas para a informação, mas não devemos esquecer que informação é diferente de 
aprendizado. A velocidade com que o saber e o saber-fazer surge e se renova são diferentes. Por exemplo, as competências adquiridas no início de um curso são obsoletas ao final dele ${ }^{4}$.

A técnica introduziu na vida moderna um jeito acelerado de ser, de modo que a educação não escapa. Mas o aprendizado nada tem a ver com a aceleração. As práticas educacionais do presente parecem ignorar isso, amalgamando esses dois vieses (informação e aprendizado), e junto com as facilidades que a tecnologia já oferece, torcem para que se crie também condições de que nossos processos internos de aprendizado e de experiência acompanhem a aceleração imposta à vida como um todo.

Retomando a citação do Alcibíades feita no início do nosso texto, é preciso concordar com Sócrates no sentido de que a despeito da disposição para se realizar um bom trabalho, os agentes sociais da educação enfrentam muitas forças, provenientes de diversos lugares, que se exprimem tanto para uma conformação com o modo de ser da sociedade sedimentada, reproduzindo fascismos, dogmatismos e práticas de sujeição; quanto para o exercício do controle através de condução de condutas que produzem indivíduos e subjetividades também castradoras e limitantes.

A educação para a vida perde o sentido quando seus objetivos se restringem a uma ideia de sujeito que tem uma finalidade específica a desempenhar na sociedade; um modo de aprender privilegiando a racionalidade; e uma teleologia subjugada aos processos da tecnociência, da lógica utilitária e econômica. Todos estes, externos à ideia primeira de educação para a construção singular e criativa da vida.

Assim, vejamos agora como poderíamos tentar resistir a essas forças, ou ainda, a essa potência da nossa cidade, das condutas de nosso povo, a fim de que obtivéssemos melhores respostas do nosso processo educativo, a partir do cuidado de si e da ideia de experiência.

\section{O Cuidado de Si e a Experiência na Educação}

\footnotetext{
${ }^{4}$ Sobre essa temática podemos lançar mão da contribuição dos estudos de Piérre Lévy. O texto utilizado para apoio nessa pesquisa foi LÉVY, P. (1999) Cibercultura. Trad. Carlos Irineu da Costa. $2^{\mathrm{a}}$ ed. São Paulo: Ed 34. 2007.

Professora de Filosofia do Instituto Federal de Educação, Ciência e Tecnologia Baiano - IFBaiano, campus Senhor do Bonfim. Mestranda em Filosofia pela UECE. Brasileira, residente em Feira de Santana - BA. Email: anisia neta@hotmail.com
} 
Uma primeira forma de entendermos o cuidado de si é a partir da relação já exposta na citação do Alcibíades, que é a do mestre com o discípulo, onde aquele tem uma orientação divina para despertar e inquietar, cuidando assim do cuidado que o discípulo deve ter de si mesmo a fim de bem governar os outros.

(...) dentro dessa perspectiva, o cuidado de si aparece como uma condição pedagógica, ética e também ontológica para a constituição do bom governante. Constituir-se como sujeito que governa implica que se tenha se constituído como sujeito que cuida de si. (FOUCAULT, 2006, 278)

Nessa relação, já vemos muita identificação com o processo de ensinoaprendizagem que queremos, no entanto, para que ele se complete é necessário que seja acrescido do sentido dado ao cuidado de si no período helênico, a partir dos estoicos e epicuristas, onde essa ideia foi sendo substituída para a relação do cuidado como um retorno a si mesmo. Em Hermenêutica do Sujeito, Foucault destaca que o modelo helenístico "tende a acentuar e privilegiar o cuidado de si, a preservar-lhe pelo menos a autonomia em relação ao conhecimento de si, cujo lugar é limitado e restrito" (FOUCAULT, 2010, 230), e que para "Sêneca, ser livre é fugir da servidão a si. O eu que precisa se libertar de tudo que pode sujeitá-lo, o eu que é preciso proteger, defender, respeitar, cultuar, honrar, prestar um culto a si mesmo". (FOUCAULT, 2010, 244).

No entanto, esse retorno a si mesmo não deve ser interpretado como um individualismo exacerbado em contrapartida das limitações de liberdade política a que Atenas estava vivendo com o Império Romano, mas uma "cultura de si" onde estão em jogo práticas e exercícios tais que transformem o sujeito e o faça viver em sociedade. É uma relação de si para consigo mesmo que reflete no entorno do sujeito.

Para que não seja entendido como uma mera repetição do mesmo, o cuidado de si é como um conhecimento e um retorno de si que ao voltar para si, se elabora e produz seus efeitos, que são de transformação do agir, expresso em um dizer verdadeiro e libertador. Esse processo desencadeia uma reciprocidade do ato de ensino-aprendizagem, onde a liberdade de ser do professor interpela e é inquirida pela construção ativa e singular das liberdades dos estudantes, a fim 
de fazer do processo educativo uma experiência de vida para uma vida não fascista.

O pensamento de Benjamin entra em concordância com isso quando, em $A$ Vida dos Estudantes, ele questiona a coerência e a unidade consciente entre os estudantes quanto a ciência, suas práticas políticas e seu comportamento ético. $O$ cuidado de si pode ser visto aqui como a prática e o empenho em estar coerente entre o que se pensa e o que se faz, entre se manter responsável com o saber e com as aplicações práticas dele, dentro de uma vida que se pretende livre e responsável, consigo mesmo e com os demais com quem convivemos.

\begin{abstract}
O cuidado de si constituiu, no mundo greco-romano, o modo pelo qual a liberdade individual - ou a liberdade cívica, até certo ponto - foi pensada como ética. Se se considerar toda uma série de textos desde os primeiros diálogos platônicos até os grandes textos do estoicismo tardio - Epícteto, Marco Aurélio... -, ver-se-á que esse tema do cuidado de si atravessou verdadeiramente todo o pensamento moral. É interessante ver que, pelo contrário, em nossas sociedades, a partir de um certo momento - e é muito difícil saber quando isso aconteceu -, o cuidado de si se tornou alguma coisa um tanto suspeita. Ocupar-se de si foi, a partir de um certo momento, denunciado de boa vontade como uma forma de amor a si mesmo, uma forma de egoísmo ou de interesse individual em contradição com o interesse que é necessário ter em relação aos outros ou com o necessário sacrifício de si mesmo (FOUCAULT, 2006, 267).
\end{abstract}

Segundo Foucault, uma primeira degenerescência do sentido do cuidado de si se deu tanto para um individualismo exacerbado, desembocando em práticas relacionadas ao empoderamento, prazer e terapia do eu, quanto no seu oposto, uma ascese rígida de tal forma que exija do sujeito uma disciplina e um rigor em prol do outro ou da sociedade, a despeito de si mesmo. Mais uma vez, em consonância com o pensamento de Benjamin em $A$ Vida dos Estudantes, as organizações dos Estudantes Livres são interpeladas por ele quanto ao assistencialismo praticado substituindo, por sua vez a responsabilidade ética com o saber e com a prática política de resistência a que se propõe uma vida de estudante, o que no fim, não é mais do que a busca e a prática, mesmo que inconfessável, de uma vida burguesa, individualista.

Professora de Filosofia do Instituto Federal de Educação, Ciência e Tecnologia Baiano - IFBaiano, campus Senhor do Bonfim. Mestranda em Filosofia pela UECE. Brasileira, residente em Feira de Santana - BA. Email: anisia neta@hotmail.com 
Por fim, outra degenerescência do sentido de cuidado de si se deu no "momento cartesiano", onde ficou encerrado na ideia de conhecimento de $\mathrm{si}^{5}$. "Parece-me que o "momento cartesiano", (...), atuou de duas maneiras, seja requalificando filosoficamente o conhece-te a ti mesmo, seja desqualificando, em contrapartida, o cuidado de si" (FOUCAULT, 2010, 15).

O cuidado de si visto dessa forma degenerada, desvirtua o seu sentido, e se aplicada para a educação, cai na esterilidade de um processo ensinoaprendizagem que se preocupa apenas para que cada indivíduo cuide de si sem a necessidade de bem cuidar do outro, através da transmissão e aquisição apenas de conhecimentos. No entanto, entender o cuidado de si para além desse viés, é falar de uma atitude geral que diz respeito a um modo de pensar e de conduzir-se.

Cuidado de si tem a ver com uma conversão do olhar para si e de exercitar-se; determina ações cujo efeito é transformador. Foucault nos lembra da relação de Sócrates com o tavão para designar essa ideia de exercício, de movimento, de transformação de si: "o cuidado de si é uma espécie de aguilhão que deve ser implantado na carne dos homens, cravado na sua existência, e constitui um princípio de agitação, um princípio de movimento, um princípio de permanente inquietude no curso da existência" (FOUCAULT, 2010, 9).

Nesse sentido, pode ser trazido para o âmbito educacional como aquele que fará do professor não apenas um mestre do cuidado, mas, um partícipe constante do processo ensino-aprendizagem; aquele que, continuamente, constituir-se-á à medida que for cuidando para que cada um também se constitua como singular na sociedade. Aquele que tem compromisso com o presente e não se conforma à burocracia de sua profissão. E nesse presente está o cuidado com os estudantes, e estes, com o bem cuidar de si, como prometeu o jovem Alcibíades à Sócrates. Conforme Foucault,

\footnotetext{
${ }^{5}$ Em acordo com essas duas degenerescências da noção de cuidado de si, Muchail conclui: "Se retomarmos os dois marcos que nos serviram de pistas, a saber, o surgimento e o quase desaparecimento filosófico da noção de "cuidado de si", diremos então - utilizando uma metáfora "médica" - que, após seu nascimento e no decurso de sua vida filosófica, a noção foi acometida por uma enfermidade de ordem moral e quase sucumbiu à morte epistemológica" (MUCHAIL, Salma Tannus. Foucault: Mestre do Cuidado. Textos sobre A Hermenêutica do Sujeito. São Paulo: Edições Loyola, 2011, 55).
}

Professora de Filosofia do Instituto Federal de Educação, Ciência e Tecnologia Baiano - IFBaiano, campus Senhor do Bonfim. Mestranda em Filosofia pela UECE. Brasileira, residente em Feira de Santana - BA. Email: anisia neta@hotmail.com 
para se conduzir bem, para praticar adequadamente a liberdade, era preciso ocupar-se de si mesmo, cuidar de si, ao mesmo tempo para se conhecer (...) e para se formar, superar -se a si mesmo, para dominar em si os apetites que poderiam arrebatá-lo" (FOUCAULT, 2006, 268).

O cuidado de si mantém uma postura constante de conversão, que requer tempo, experiência e exercício. São as práticas de si que redundarão numa transformação de si e em ações de cuidado mútuo. A discrepância entre teoria e prática pedagógica se faz no momento em que essa parte do cuidado de si não é entendida. As práticas e os exercícios do cuidado de si são tomados como uma criação de um habitus, um processo de ruminar (grübeln) (BENJAMIN, 1984, 198) conteúdos que foram iluminados pelo conhecimento de si, mas que necessitam serem digeridos e sedimentados pela experiência.

Para Walter Benjamin, em textos como O Narrador, Experiência e Pobreza (1994), percebemos o conceito de experiência como o que produz uma sabedoria, um aprendizado, mas para isso, é preciso de tempo, silêncio, vivência, ou seja, ritmo desacelerado para chocar seus ovos. (BENJAMIN, 1994; 1986).

Aqui, verificamos o quanto a experiência benjaminiana bem como os exercícios e as práticas do cuidado de si foucaultiano precisam de tempo para maturar e operar a transformação do agir. No processo do cuidado de si, o conhecimento ou a iluminação sobre si mesmo que arrebata o sujeito é apenas a primeira parte do processo. Após essa iluminação, o cuidado de si continua a partir do trabalho sobre si mesmo, um labor que se faz demorado e que requer exercícios e práticas para a elaboração de si. Esse período de elaboração de si pode ser entendido, junto com Benjamin, por um processo que requer tempo, silêncios, ruminação a fim de que se choque os ovos da experiência, ou seja, para que se obtenha os efeitos da verdade, a transfiguração do sujeito dado pelo retorno sobre o sujeito.

Foucault alerta que "cuidar de si é uma regra coextensiva à vida" (FOUCAULT, 2010, 221), não diz respeito apenas ao período da juventude até a vida adulta, o período onde os gregos estavam entregues aos pedagogos, mas é extensivo a toda a vida, é um exercício que está para além de um período de formação, antes, é um preceito para bem viver. 
E se a educação que queremos é aquela que nos prepara integralmente para a vida, o cuidado de si deve ser empregado a fim de fazer com que todos os agentes envolvidos no processo de educação realizem os exercícios e as práticas do cuidado de si, levando-os além do conhecimento de si e de um mergulhar em si mesmo, mas com as devidas transformações do agir.

Dentro de uma proposta de educação para a vida e que requer um aprendizado para uma transformação do sujeito, verificamos o quanto a aceleração da vida e o uso irrefletido das tecnologias da informação caminham distantes desse processo almejado. Benjamin ao se referir sobre a informação, nos lembra que esta é uma forma de comunicação que surge com a ascensão da burguesia e do alto capitalismo, cujo maior instrumento era a imprensa, e que ameaça a imaginação e a criação, o saber e a educação como um todo. A informação aspira a verificação imediata; ela carrega consigo todas as explicações. Não há espaço para uma livre interpretação, antes, é fechada e não ampla. (BENJAMIN, 1994).

A partir de Benjamin podemos entender o quanto a informação e o aprendizado são distintos, bem como o tanto que a aceleração da vida no processo educacional afeta 0 desenvolvimento do aprendizado e do objetivo último da educação que é o mesmo que Foucault diz sobre o cuidado de si: uma coextensão da vida, não se reduzindo a um período formativo específico.

Assim, entendemos que o processo de formação pedagógica pode ser entendida como uma experiência que não se encerra num período específico, nem se restringe a uma aquisição de conhecimentos posteriores à formação inicial através de cursos, mas que diz respeito a uma postura de vida, na tentativa de ver o humano em sua totalidade; não como as tradições antigas, mas que enquadre teoria e prática, vida pessoal e profissional, formação humana globalizante e voltada para uma vida não fascista, aplicando o conceito de cuidado de si às singularidades (sua e dos estudantes) e não aos indivíduos.

Pensemos em uma educação do cuidado de si e da experiência e não do "formar" para pensar práticas de si que equivalem sujeito e verdade, bem como um cuidado com o outro, que é ético e que se faz político, para a construção de si desse outro.

Professora de Filosofia do Instituto Federal de Educação, Ciência e Tecnologia Baiano - IFBaiano, campus Senhor do Bonfim. Mestranda em Filosofia pela UECE. Brasileira, residente em Feira de Santana - BA. Email: anisia neta@hotmail.com 
Lembremos que o sujeito cognoscente é aquele que se quer desconstruir. Observa-se, nesse conceito, a sintonia com o agora do cognoscível bejaminiano (Jetzt der Erkennbarkeit) (BENJAMIN, 1989, 173), onde todo o conhecimento é convocado a reagir diante de uma situação que exige urgência, tal qual em uma ação política. A educação, a partir da experiência formativa, ao encontrar teoria e prática, lembra 0 quanto 0 saber se faz também na prática e sem necessariamente ser um processo do sujeito de conhecimento, mas pode ser do sujeito que sente, que se emociona, que aprende a partir das experiências não faladas, não racionalizadas, não capturadas por conceitos.

\section{[Re]Existências - Considerações Finais}

À guisa de conclusão, resgatemos o texto de Platão, onde Sócrates temia o insucesso de Alcibíades no intento do cuidado de si e da justiça, bem como o dele mesmo no intento de escapar da potência da cidade de Atenas, o que realmente aconteceu.

É difícil imaginar corpos frágeis e minúsculos indo de encontro a forças biopolíticas diversas e vencê-las. Mais fácil seria o descuido com a justiça e consigo mesmo, ou ainda, que as forças sejam imponentes e demasiado concretas de tal modo que não se possa escapar ileso.

Muitos são os vieses que atravessam o processo educacional, em específico o processo ensino-aprendizagem, que envolve a construção dos saberes a partir de seus agentes: professor-estudantes. E nesse texto, propomos o cuidado de si a partir de Michel Foucault e a experiência a partir de Walter Benjamin como peças-chave para desarmar esses pontos de intersecção que se sobrepõem a uma educação que se pretende para a vida, respeitando a cidadania e a justiça.

Assim, dispomos de um modo de existência outra que resiste às forças que se interpõem no decurso do caminho educacional. São resistências que se tornam re-existências, reformuladas, ressignificadas, refeitas, reinventadas, reelaboradas. São formas de existir que entendem a educação não como um ponto, ou um rito ao qual passamos na vida, mas como constituintes da própria vida. Como processos que nos acompanham na existência, e que esta, por sua 
vez, não se dá sozinha, mas em sociedade. Assim, fazemo-nos e colaboramos para que os outros também se façam singulares e cooperadores de vidas não fascistas, não individualizantes, não limitadoras nem castradoras, antes, vidas que se dispõem ao aprendizado da convivência, da mutualidade, da afirmação de si, do prazer e da responsabilidade de ser no mundo consigo mesmo e com os outros.

\section{REFERÊNCIAS}

BENJAMIN, Walter. Magia e Técnica, Arte e Política: ensaios sobre literatura e história da cultura. Trad. Sérgio Paulo Rouanet. $7^{\text {a }}$ ed. São Paulo: Brasiliense, 1994. 253p. (Obras Escolhidas; vol I).

. Origem do drama barroco alemão, Tradução de Sérgio Paulo Rouanet, São Paulo: Brasiliense, 1984.

A Vida dos Estudantes. In : Documentos de cultura, documentos de barbárie: escritos escolhidos. Trad. Wilhelm Bolle (Willi Bolle). Apresentação Celeste H. M. Ribeiro de Sousa. São Paulo: Cultrix: Editora da Universidade de São Paulo. 1986. 201 p.

Hábitos e atenção In_: Rua de Mão Única, Tradução de Rubens Rodrigues Torres Filho e José Carlos Martins Barbosa, São Paulo: Brasiliense, 1987.

Charles Baudelaire - um lírico no auge do capitalismo, Tradução de José Carlos Martins Barbosa e Hemerson Alves Baptista, São Paulo: Brasiliense, 1989.

FOUCAULT, Michel. A Hermenêutica do Sujeito: curso dado no Collège de France (1981 - 1982). Trad. Marcio Alves da Fonseca e Salma Tannus Muchail. $3^{\mathrm{a}}$ ed. São Paulo: WMF Martins Fontes. 2010. 505p.

A Ética do Cuidado de Si como Prática da Liberdade. In : Ética, Sexualidade, Política. Organização e seleção de textos Manoel Barros de Motta; tradução Elisa Monteiro, Inês Autram Dourado Barbosa. 2a ${ }^{\mathrm{a}}$. ed. Rio de Janeiro: Forense Universitária, 2006. 326p. (Ditos e Escritos V)

Subjetividade e Verdade. In_: Filosofia, Diagnóstico do

Presente e Verdade. Organização, seleção de textos e revisão técnica Manoel Barros de Motta; tradução Abner Chiquieri. - 1aㅡ ed. - Rio de Janeiro: Forense Universitária, 2014. 377p. (Ditos e Escritos X)

Professora de Filosofia do Instituto Federal de Educação, Ciência e Tecnologia Baiano - IFBaiano, campus Senhor do Bonfim. Mestranda em Filosofia pela UECE. Brasileira, residente em Feira de Santana - BA. Email: anisia neta@hotmail.com 
LÉVY, Pierre. (1999) Cibercultura. Trad. Carlos Irineu da Costa. $2^{2}$ ed. São Paulo: Ed 34. 2007. 264p.

MUCHAIL, Salma Tannus. Foucault: Mestre do Cuidado. Textos sobre $A$ Hermenêutica do Sujeito. São Paulo: Edições Loyola. 2011. 135p.

PLATÃO. Diálogos: Fedro - Cartas - Primeiro Alcibíades. Trad. direta do grego: Carlos Alberto Nunes. 2a edição Revisada. Belém: EDUFPA, 2007. 290p.

PLATO. Alcibíades I. Translated by Benjamin Jowett. Project Gutenberg Etext \#1676: Champaign: Carnegie-Mellon University. 1999. 56p. 